\title{
KONTEKSTUALISASI KONSEP JODOH, SAKINAH, MAWADAH, WARAHMAH DALAM AL-QUR'AN
}

\author{
Fawait Syaiful Rahman \\ Sekolah Tinggi Islam Blambangan Banyuwangi \\ fawaidsyaifulrahman@gmail.com
}

\begin{abstract}
Islam limits the pattern of interaction between men and women outside of marriage so that their respective honor can be maintained. In humans, there is a tendency of animal tendencies that have the potential to lead to prohibited cases (mungkarat or mubarramat). Islam also regulates the provisions if a man and woman want a halal relationship as well as a reward value in the framework of marriage. An ideal marriage is generally defined as a marriage that is the result of one's own choice without any outside intervention, the two partners are never heard of fighting and arguing, and a married couple is supported by an established economy, such family conditions are considered ideal families. After several weeks or more, the news was heard that the husband and wife were divorced, even though at the beginning of the marriage they had received a prayer "hopefully they will become a sakinah family, mawadah, warahmah and mate in the hereafter" could not prevent the intention to separate. The research method in this article uses a qualitative literature approach. The conclusion from the study and analysis of the text of the verses of the Qur'an regarding the concept of mate and the concepts of sakinah, mawadah, warahmah in the Koran is mentioned differently
\end{abstract}


by Allah SWT. The concept of mate is said to use Arabic khalaqah, and the concepts of sakinah, mawadah, warahmah are spoken in Arabic ja'ala. The consequence of disclosing the concept of a mate using lafadz khlaqah means that something is the personal right of Allah SWT and humans do not have the effort to intervene, while the disclosure of the concepts of sakinah, mawadah, warahmah uses lafadzja'ala, this means that human intervention is needed in building a family that is ideal.

Keywords: the concept of mate, Sakinah, Mawadah, Warahmah

\section{Pendahuluan}

Pernikahan sejatinya bagian dari fitrah kehidupan. Pernikahan merupakan sarana reproduksi dari sirkulasi roda kehidupan. Manusia sebagai "pemimpin" atau khalifah fii al-ardi dibatasi dengan umur. Salah satu sumber hadist menyebutkan umur manusia berkisar antara 60 sampai 70 tahun, $^{2}$ sedangkan umur alam semesta lebih panjang dibandingkan umur manusia, ${ }^{3}$ sehingga adanya alternatif solutif yang dapat mengatasi umur manusia dan umur alam semesta yang tidak berbanding lurus menjadi keniscayaan.

Islam membatasi pola interaksi antara laki-laki dan perempuan diluar pernikahan, agar kehormatan masing-masing dapat terjaga. Di dalam diri manusia tersimpan kecenderungan-kecenderungan hewani ${ }^{4}$ yang berpotensi menjerumuskan pada perkara yang dilarang (mungkarat

\footnotetext{
${ }^{1}$ QS. Al-Baqarah (2):30

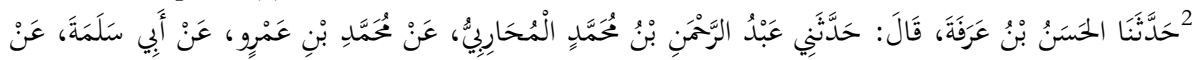

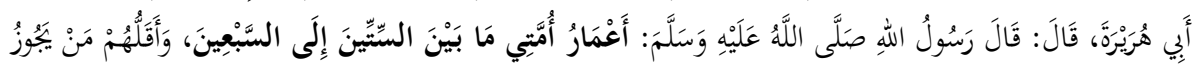

${ }^{3}$ Kiamat adalah hari kehancuran alam semesta, dimana pada hari tersebut wajah-wajah tertunduk malu, bekerja keras lagi kepayahan, memasuki api yang sangat panas (neraka), diberi minum (dengan air) dari sumber yang sangat panas, mereka tiada memperoleh makanan selain dari pohon yang berduri, beginilah sekelumit gambaran hari Kiamat. Kedatangannya pasti terjadi namun dirahasiakan oleh Allah SWt, bahkan Rasulullah sendiri tidak mengetahui selain tanda-tanda kapan kiamat akan datang, ebagaimana disebutkan di dalam al-Qur'an QS. Al-Ghaasiyyah ayat 1 sampai 6.

${ }^{4}$ Kecenderungan hewani di dalam bahasa al-Qur'an disebut dengan potensi buruk manusia. Allah SWT menyempurnakan manusia dengan dua potensi, ada potensi baik dan ada potensi buruk sebagaimana disebutkan di dalam al-Qur'an Qs. 
atau mubarramat). Islam juga mengatur ketentuan-ketentuan ${ }^{5}$ apabila lakilaki dan perempuan menginginkan hubungan halal sekaligus bernilai pahala dalam bingkai pernikahan.

Setelah menikah, segala bentuk aktivitas suami istri menjadi sumber ladang pahala. Hal ini tidak lepas dari hakikat pernikahan yang sebenarnya mengikuti sunah Rasulullah SAW, sebagaimana bunyi hadist;

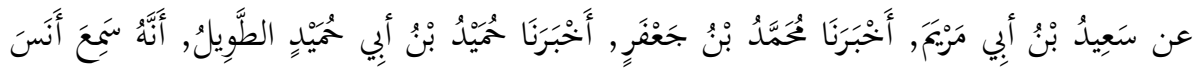

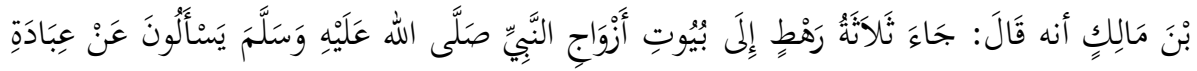

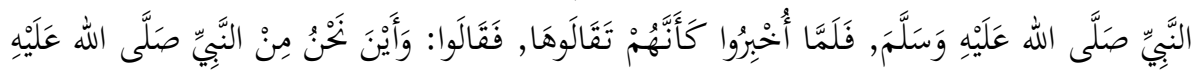

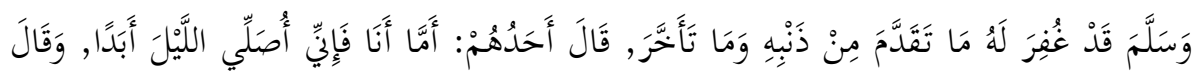

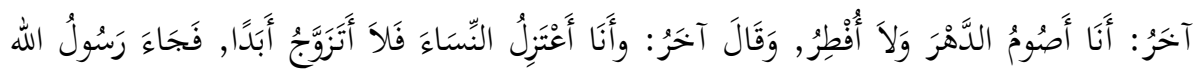

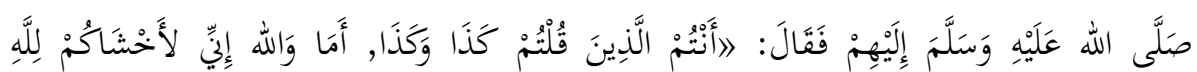

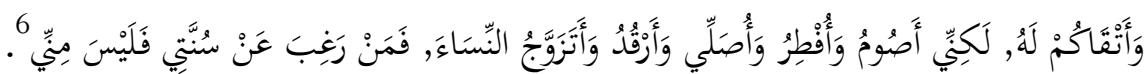

Dari Said Bin Abi Maryam, bahwa Mubammad Bin Ja'far memberitahu kami, Abmid Bin Humaid al-Thawil memberitahu kami, bahwa Humaid mendengar Anas Bin Malik berkata; ada tiga orang berbeda suku datang ke rumah istri-istri Nabi shallallabu 'alaibi wa sallam menanyakan tentang bagaimana ibadahnya Nabi shallallabu 'alaibi wa sallam. Setelah mereka diberitabu, mereka seolab-olah menganggap amat sedikit saja ibadah Nabi shallallabu 'alaibi wa sallam itu. Mereka lalu berkata: "dimanakah kita ini, maksudnya: kita ini jauh perbedaannya kalau dibandingkan dari Nabi shallallahu 'alaibi wa sallam sedangkan beliau itu telah diampuni segala dosanya yang lampau dan yang kemudian." Seorang dari mereka itu berkata: "adapun saya ini, maka saya bershalat semalam suntuk selama-lamanya." Yang lainnya berkata: "Adapun saya, maka saya berpuasa sepanjang tabun dan tidak pernab saya berbuka." Yang seorang lagi berkata: "Adapun saya, maka saya menjaubi para wanita, maka sayapun tidak akan kawin selamalamanya." Rasulullah shallallabu 'alaibi wa sallam kemudian

\footnotetext{
${ }^{5}$ Di dalam Fiqh ketentuan pernikahan berupa syarat dan rukun Pernikahan. Bagi lakilaki dan perempuan apabila menginginkan hubungan halal sesuai aturan syariah maka harus memenuhi syarat dan rukun di dalam pernikahannya.

${ }^{6}$ Muhallab Bin Ahmad Bin Abi Sufrah Asid Bin Abdillau, Mubktasor Al-Nasib Fii Tahdribi Al-Kitab Al-Jami' Al-Shabih, 2nd ed. (Riyadl: Daru al-Ttauhid, 1430), 376.
} 
mendatangi mereka lalu bersabda: "Engkau semuakab yang mengatakan demikian, demikian? Wahai, demi Allah, sesunggubnya saya ini adalah orang yang tertaqwa -paling bertaqwa- diantara engkau semua kepada Allab dan tertakut -paling takut-kepadaNya, tetapi saya juga berpuasa dan juga berbuka, sayapun bershalat tetapi juga tidur, juga saya suka kawin dengan para wanita. Maka barangsiapa yang enggan pada cara perjalananku -sunnabku-, maka ia bukanlah termasuk dalam golonganku." (Muttafaq 'alaib)

Hadist rawayat Said Bin Abi Maryam, bercerita kejadian masa lalu di masa Rasulullah SAW. Ada tiga sahabat mendatangi kediaman istri-istri Rasul untuk bertanya tentang ibadah suaminya, dan setelah mereka mendapat jawaban, ketiga sahabat tadi berfikir ibadah mereka lebih bernilai, satu persatu diantara mereka bercerita tentang ibadah masingmasing. Kemudian Rasulullah memberi tanggapan atas pernyataan mereka dengan kalimat "demi Allah, saya lebih takut dan lebih takwa kepada-Nya, tetapi saya berpuasa, saya juga berbuka, saya juga shalat, saya juga tidur dan saya juga menikah dengan perempuan", dari runtutan kalimat hadist disimpulkan bahwa pernikahan adalah salah satu ibadah yang telah dilakukan Rasulullah SAW.

Teks hadist riwayat Said Bin Abi Maryam di atas mengandung dua substansi yang dapat menjadi dasar tentang pernikahan bagian dari ibadah., pertama pertanyaan sahabat kepada istri-istri Rasulullah SAW tentang ibadah suaminya, dan kedua sebagian isi tanggapan sabda Rasulullah SAW kepada sahabat menyebutkan tentang pernikahan, sehingga pernikahan difahami menjadi bagian dari ibadah. ${ }^{7}$ Di dalam alQur'an QS. An-Nisa' ayat 3 menyebutkan secara tegas tentang anjuran pernikahan;

Dan jïka kamu takut tidak akan dapat Berlaku adil terbadap (bakhake) perempuan yang yatim (bilamana kamu mengawininya), Maka kawinilah wanita-wanita (lain) yang kamu senangi : dua, tiga atau empat. kemudian jika kamu takut tidak akan dapat Berlaku adil, Maka (kawinilah) seorang saja, atau budak-budak yang kamu miliki. yang demikian itu adalah lebih dekat kepada tidak berbuat aniaya.

Penyebutan pernikahan pada QS. An-Nisa' ayat 3 berupa kalimat perintah (amr) yaitu lafadz "fankibu", sedangkan lafadz perintah di dalam ushul fiqh merujuk pada dua konsekuensi hukum, bisa tergolong perkara wajib atau perkara sunah. Apabila lafadz "fankibu” QS. An-Nisa' ayat 3

\footnotetext{
${ }^{7}$ Kesimpulan ini didasarkan pula kepada ayat al-Qur'an QS. An-Nisa ayat 3
} 
diarahkan pada hukum wajib sepertinya kurang tepat, karena dalil lain yang memberi indikasi tentang pernikahan merupakan perbuatan sunah nabi juga ada. Kalimat perintah bisa mengarah pada hukum wajib selama tidak ada dalil lain yang memalingkannya dari hukum wajib. Sedangkan dalil-dalil sunah yang menyinggung pernikahan termasuk sunah nabi banyak ditemukan.

Salah satu dalil yang menyebutkan pernikahan perkara sunah adalah hadist sabda Raulullah SAW berupa;

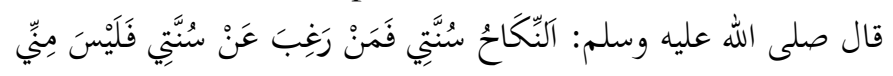

Pernikahan adalah sunabku, maka barang siapa yang tidak suka sunabku maka iya bukan termasuk golonganku.

dikalangan intelektual muslim hadist ini sangat populer dan selalu menjadi rujukan, apakah sebagai bahan tulisan ilmiah atau bahan ceramah dalam undangan pernikahan. Dari penjelasan beberapa hadist dan ayat tentang pernikahan dapat disimpulkan bahwa pernikahan bagian dari ibadah dan tergolong perbuatan sunah. Alasan pertama, pernikahan dipraktekkan langsung oleh Rasulullah SAW., dan alasan kedua hadist yang menunjukkan perintah menikah diarahkan pada hukum sunah, bukan pada hukum wajib banyak ditemukan.

Rasulullah SAW dalam berinteraksi selalu mencerminkan kepribadian mulia $^{8}$ dan akhlak terpuji, baik interaksi bersama para sahabat, dengan para istri-istri nya, orang-orang kafir, terlebih akhlak kepada Allah SWT. Siti Aisyah ra. ketika ditanya tentang akhlak Rasul, iya menjawab akhlak Rasulullah SAW adalah al-Qur'an. ${ }^{9}$ Selian siti Aisyah ra. sayyidina Ali ra. juga menyampaikan bahwa akhlak yang agung adalah akhlak al-Qur'an, dan Rasulullah SAW satu-satunya manusia berperangai akhlak al-Qur'an;

$$
\text { وقال عليّ: الخلق العظيم آداب القرآن }
$$

Budi pekerti atau akblak mulia adalah akblak al-Qur'an

al-Qur'an selain mencerminkan akhlak Rasulullah SAW juga menjadi sumber utama agama Islam. Di dalamnya memuat sejarah zaman nabi masa lalu, hukum, etika, dan membacanya bernilai ibadah, inilah keistimewaan al-Qur'an dan keistimewaan Rasulullah SAW. Barang siapa

${ }^{8}$ Disebutkan di dalam al-Qur'an QS. Al-Qalam ayat 4;

Dan Sesungguhnya kamu benar-benar berbudi pekerti yang agung.

$$
9 \text { سئلت عائشة رضي الله عنها عن خلقه فقالت كان خلقه القرآن }
$$

Siti Aisyah ra. ditanya tentang akhlak Rasulullah SAW, beliau menjawab akhlak Rasulullah SAW adalah al-Qur'an. 
yang mengerti isi kandungan al-Qur'an, bahkan menjadi penghafal sekaligus seorang ahli tafsir, maka Allah SWT memberikan jaminan surga surga kepadanya, tidak hanya itu setelah meninggal dunia jasadnya harum dan tetap utuh di dalam kubur.

Selain al-Qur'an, hadist juga termasuk sumber ajaran Islam. Tingkatan urutan hadsit berada nomor dua setelah al-Qur'an, sehingga mempelajari ilmu-ilmu tentang al-Qur'an dan hadist sekaligus mengamalkan nya merupakan keharusan. Menurut para ulama', mempelajari dan menguasai perangkat untuk memahami sumber ajaran Islam dalam satu daerah dikategorikan fadlu kifayah, apabila sebagian orang sudah ada yang mengusai berbagai perangkat ilmu agama Islam maka menjadi gugur kewajiban bagi yang lain. Tujuan mempelajarinya adalah menghindarkan diri dari penafsiran salah dan sesat sekaligus menyesatkan serta sebagai bekal perjalanan selama mengarungi bahtera kehidupan yang dipenuhi dengan ujian dan cobaan..$^{10}$

Siti Aisyah ra, menikah dengan Rasulullah SAW saat berumur 6 tahun, ${ }^{11}$ umur yang menggambarkan sosok wanita sangat muda. Setelah siti Aisyah ra. menikah dengan Rasulullah SAW tidak langsung bersama dalam satu rumah sampai siti Aisyah ra, berumur 10 tahun. Hal ini membuktikan bahwa motivasi Rasulullah SAW menikahi siti Aisyah ra, bukan mengikuti hawa nafsu, karena jika iya, Rasulullah SAW tidak perlu menunggu cukup lama untuk berkumpul satu rumah bersama siti Aisyah ra.

Selama bersama dengan Rasulullah SAW, Siti Aisyah ra, pernah dipanggil dengan panggilan Humaira, panggilan sangat romantis. ${ }^{12}$ Hadist sahih yang menjelaskan hal tersebut tidak sedikit, diantaranya;

${ }^{10}$ Disebutkan di dalam al-Qur'an QS. Al-Baqarah ayat 155;

Dan sungguh akan Kami berikan cobaan kepadamu, dengan sedikit ketakutan, kelaparan, kekurangan harta, jiwa dan buab-buahan. dan berikanlah berita gembira kepada orang-orang yang sabar.

${ }^{11}$ Keterangan umur siti Aisyah, ra saat dinikahi Rasulullah SAW ada dua pendapat. Pendapat pertama mengatakan usia menikah siti Aisyah, ra 6 atau 7 tahun dan usia 10 tahun berkumpul bersama Rasulullah. Pendapat lain didasarkan pada riwayat Abdurrahman bin Abu Abi Zannad dan Ibnu Hajar al-Asqalani menyebutkan bahwa usia siti Aisyah ra ketika berumah tangga adalah 19 atau 20 tahun. https://islam.nu.or.id/post/read/88535/alasan-rasulullah-menikahi-aisyah.

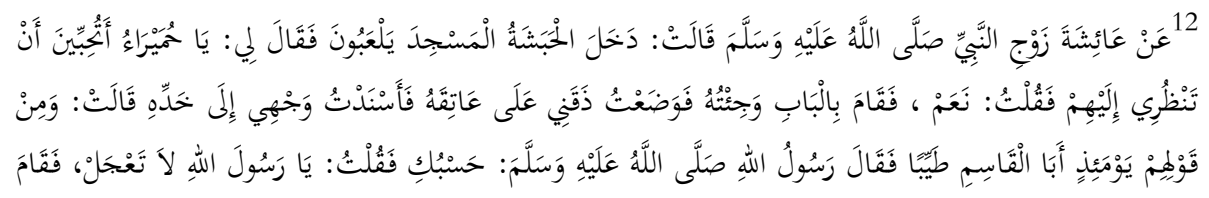




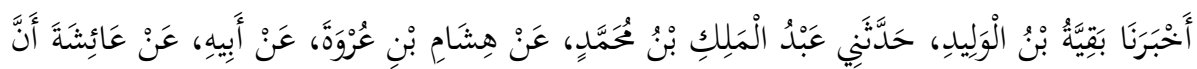

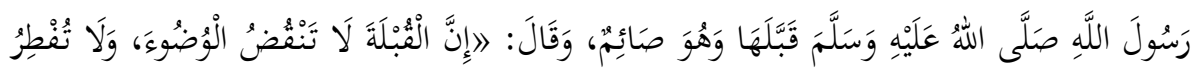

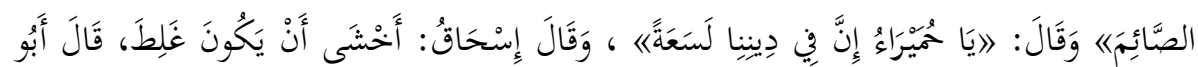

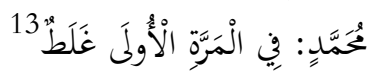

Panggilan Humaira dari Nabi kepada siti Aisyah ra. menandakan ahklah luhur Rasulullah SAW kepada istrinya. Panggilan Humaira tersebut bukan mengajarkan kepada umatnya untuk memanggil istri mereka dengan panggilan Humaira pula. Substansi pelajaran lebih luas dari hadits di atas adalah mengikuti seluruh ajaran Rasulullah SAW, termasuk dalam memperlakukan istri-istri kita dengan sangat baik. Sebagai umat Rasulullah SAW seyogyanya dalam segala aktivitas menjadikan Nabi Muhammad suri teladan. Kemuliaan pribadi Rasulullah SAW adalah wujud dari aktualisasi agama Islam kafah, agama yang mengajarkan saling menjaga harkat dan martabat satu sama lain, dan agama yang mengedepankan prinsip moderat, maka menjadikan Rasulullah SAW sebagai suri teladan terbaik dimuka bumi merupakan keniscayaan.

Kondisi kehidupan telah mengalami perubahan luarbiasa sejak era Rasulullah SAW, para sahabat, tabiin, tabiin-tabiin, ulama mazhab hingga masa saat ini. Pengamalan ajaran Islam di tengah masyarakat semakin tereduksi, kualitas ibadah dan muamalah mengalami disrupsi, sedangkan orientasi pendidikan mulai mengalami pergeseran dari etis-humanitisidealis ke arah pragmatis-materalis. Semua khalayak saat ini telah merasakan kemajuan iptek dan globalisasi sebagai wujud modernisasi. Iptek dan globalisasi semakin eksis menghipnotis masyarakat Indonesia berpaling dari ajaran dan spirit agama Islam sebagaimana telah dicontohkan Rasulullah SAW terlebih era transmisi industri 4.0..

Pernikahan sangat identik dengan perceraian. Kita sudah melihat dan merasakan, jumlah angka perceraian terus mengalami lonjakan, dan meningkat luar biasa pada musim pandemi Covid-19 ${ }^{14}$ saat ini.

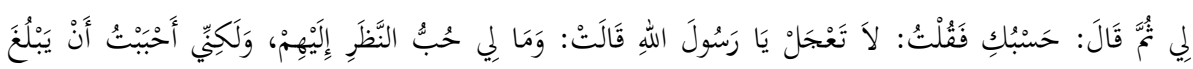

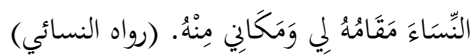

${ }^{13} \mathrm{Abu}$ Ya'kub Ishaq Bin Ibrahim, Musnad Ishaq Bin Ruhawiyah, 2nd ed. (Madinah: Maktabatu al-Iman, 1412), 172.

14 https://news.detik.com/berita-jawa-barat/d-4984379/pandemi-corona-gangguekonomi-perceraian-di-cianjur-berpotensi-meningkat, 12 April 2020. Disebutkan juga pada https://fin.co.id/2020/07/11/selama-pandemi-corona-kasus-perceraianmelonjak/, 11 Juli 2020 
Penyebaran Covid-19 di tanah air melumpuhkan berbagai sektor kehidupan. Kebijakan pemerintah menerapkan Pembatasan Sosial Berskala Besar (PSBB), sosial distancing, dan berjaga jarak, membuat pelaku usaha UMKM sulit bernafas, pabrik produksi banyak mengalami gulung tikar, usaha perhotelan tidak jalan, sehingga pilihan terakhir adalah merumahkan karyawan dan phk. Secara umum penyebab tingginya angka perceraian adalah keterbatasan ekonomi. Masyarakat menengah dan miskin sudah mengalami kesulitan ekonomi sebelum Covid-19 masuk tanah air, dan semakin merasakan kesulitan ekonomi setelah Covid-19 masuk di Indonesia. Selain kasus perceraian, perbuatan asusila dan pelecehan seksual, pemakai dan pengedar Narkoba, pencurian, penggelapan uang Negara (korupsi), hingga pembunuhan semakin marak terjadi. Tingkah laku kurang terpuji sebagaimana di atas terjadi di negara Indonesia, negara gemah ripah loh jinawi, sungguh sangat ironi.

Salah satu kebiasaan setelah menikah, pasangan suami istri mendapat ucapan doa selamat dari famili, kerabat, tetangga, dan temantemannya. Doa yang sering diucapkan kepada pasangan suami istri dari kalangan muslim adalah semoga menjadi keluarga sakinah, mawadah, wa-rahmah, dan semoga dikaruniai putra-putri saleh dan salehah. Di dalam doa tersebut, tersimpan harapan besar dari kedua mepelai dan keluarga masing-masing. Diantara harapan besar itu, pasangan yang baru menikah dapat membina dan membangun hubungan rumah tangga tenteram, damai, ajek, dan sukses baik dunia dan akhirat.

Secara umum istilah "pernikahan ideal" dimaknai dengan pernikahan hasil pilihan sendiri yang tidak ada intervensi dari luar, kedua pasangan tidak pernah terdengar berseteru dan berselisih, ditambah pasangan suami istri ditopang ekonomi mapan, kondisi demikian dianggap ciri dari keluarga ideal. Setelah beberapa minggu bahkan lebih, terdengar kabar suami istri sudah bercerai, meski diawal pernikahan mendapat doa "semoga menjadi keluarga sakinah, mawadah, wa-rahmah dan jodoh dunia akhirat" belum tentu membuat pernikahan sesuai harapan.

Fakta di atas merupakan salah satu dari kompleksitas problematika pernikahan, dan masih banyak fakta-fakta lainnya. Sehingga fokus kajian diarahkan pada "dimana posisi konsep sakinah, mawadah, wa-rahmah di dalam pernikahan? Apakah konsep sakinah, mawadah, wa-rahmah menjadi satu kesatuan dengan pernikahan atau merupakan perkara lain (Syai'un Akhor)? Dan apakah terdapat makna filosofis dibalik doa sakinah, mawadah, wa-rahmah yang harus digali, dipelajari, dan difahami oleh umat muslim?” 
Artikel ini membahas konsep jodoh, sakinah, mawadah, warahmah dalam pernikahan sekaligus menjadi jawaban dari fokus kajian dimuka. Objek analisis adalah ayat-ayat spesifik yang membahas konsep sakinah, mawadah, wa-rahmah dalam pernikahan. Kajian dan hasil dari analisis artikel ini dirasa sangat penting, mengingat penjelasan yang ada tentang konsep sakinah, mawadah, wa-rahmah dari sumber buku dan artikel belum tersaji secara utuh. Semoga hadirnya artikel ini dapat memberi wawasan dan ilmu baru bagi para pembaca, sekaligus menjadi bekal berkeluarga demi menciptakan model keluarga ala Raslullah SAW dan dapat meminimalisir laju perceraian di tanah air.

\section{Metode Penelitian}

Metode penelitian yang digunakan adalah kualitatif dengan berorientasi pada teks-teks ayat spesifik konsep sakinah, mawadah, dan rahmat dalam pernikahan. Pendekatan Tafsir Madlu'i digunakan sebagai media analisis agar kajian tidak mengarah kemana-mana. Selanjutnya melakukan eksplorasi dan pengelompokan teks-teks ayat sesuai tema kajian tentang konsep sakinah, mawadah, dan rahmat dalam pernikahan. ${ }^{15}$ Sedangkan jenis penelitian adalah penelitian kepustakaan atau library research. ${ }^{16}$

\section{Hasil dan Pembahasan}

A. Korelasi Ayat Konsep Sakinah, Mawadah, dan Rahmat dengan Ayat lain

Teks ayat tentang konsep Sakinah, Mawadah, dan Rahmat secara tegas disebutkan di dalam al-Qur'an QS. Ar-Ruum ayat 21;

\footnotetext{
${ }^{15}$ Metode kualititatif adalah metode penelitian yang digunakan untuk meneliti pada kondisi obyek yang alamiah, (sebagai lawannya adalah eksperimen) dimana peneliti adalah sebagai instrumen kunci. Peneliti kualititatif juga diartikan dengan penelitian yang datanya dinyatakan dalam bentuk verbal dan dianalisis tanpa menggunakan teknis statistik. Mundir menjelaskan penelitian kualititatif adalah penelitian yang datanya dinyatakan dalam keadaan sewajarnya atau apa adanya (naturalistik, natural setting), tidak dirubah dalam bentuk simbol-simbol atau bilangan dengan maksud untuk menemukan kebenaran dibalik data yang objektif dan cukup.

${ }^{16}$ Penelitian kepustakaan adalah penelitian yang dikerjakan untuk memecahkan suatu masalah yang bertumpu pada studi kritis terhadap bahan-bahan pustaka dan hasil penelitian terkait yang disajikan dengan cara baru. Bandingkan dengan Fawait Syaiful Rahman, "Analisis Maqashid Syari'ah Jasser Auda Terhadap Izin Perkawinan Dan Perceraian Bagi Pegawai Negeri Sipil," Momentum : Jurnal Sosial Dan Keagamaan 7, no. 1 (2019): 35-58, https://doi.org/10.29062/mmt.v7i1.15.
} 
Dan di antara tanda-tanda kekuasaan-Nya ialah Dia menciptakan untukmu isteri-isteri dari jenismu sendiri, supaya kamu cenderung dan merasa tenteram kepadanya, dan dijadikan-Nya diantaramu rasa kasih dan sayang. Sesungguhnya pada yang demikian itu benar-benar terdapat tanda-tanda bagi kaum yang berfikir.

Ayat 21 QS. ar-Ruum merupakan satu-satunya ayat yang memuat konsep sakinah, mawadah, dan rahmat. Meski demikian, pemahaman terhadap ayat tersebut tidak bisa dipisahkan dari ayat sebelum dan sesudahnya guna memperoleh hasil komprehensif. Kajian analisis terhadap ayat 21 QS. Ar-Ruum perlu melibatkan ayat sesudahnya yaitu ayat 20 , dan ayat sebelumnya ayat 22 sampai ayat 24. Ini dimaksudkan agar pemahaman objektif dan menyeluruh dapat diperoleh. Selain alasan tersebut, terdapat keterangan di dalam kitab tafsir bahwa al-Qur'an bagaikan satu kalimat, dimana satu ayat dengan ayat yang lain saling melengkapi dan saling menafsirkan, ${ }^{17}$ sehingga kajian pada ayat 21 QS. Ar-Ruum dilakukan secara komparasi dengan melibatkan ayat sesudah dan sebelumnya. Metode ini sama sekali tidak mengurangi eksistensi sunah atau hadist sebagai penjelas keumuman al-Qur'an.

QS. Ar-Ruum ayat 21 dengan ayat sebelumnya, yaitu ayat 22, 23, dan 24 sekaligus ayat sesudahnya ayat 20 menjelaskan tentang sebagian dari tanda keagungan ${ }^{18}$ dan kesempurnaan kuasa Allah SWT. Ayat-ayat tersebut menjadi bukti keesaan-Nya dan menunjukkan Allah SWT ada atau wujud. Tanda keberadaan Allah SW'T tertera pada masing-masing ayat, diantaranya Allah menciptakan manusia dengan debu, menciptakan langit dan bumi sekaligus perbedaan bentuk bahasa dan warna kulit manusia. Keterangan lebih rinci akan dibahas secara bertahap di bawah ini.

Ayat 20 sampai ayat 22 QS. Ar- Ruum membahas tentang makhluk ciptaan Allah SWT, sedangkan ayat 23 dan 24 membahas tanda kekuasaan-Nya. Pada ayat 20 QS. Ar-Ruum berbicara awal mula penciptaan manusia dari tanah atau debu, sebagaimana difirmankan;

Dan di antara tanda-tanda kekuasaan-Nya ialah Dia menciptakan kamu dari tanah, kemudian tiba-tiba kamu (menjadi) manusia yang berkembang biak.

\footnotetext{
${ }^{17}$ Umar Bin Abdu Al-Aziz, An-Naqsu Mina an-Nassi Hakiqatu Wa Hikmatubu Wa Astaru Dralika Bi Al-Ibtijaji Bi as-Sunati Al-Hadiyati, 1st ed. (Madinah: t.p., 1988), 71.

18 Abu al-Fada' Ismail, Tasfir Al-Qur'an Al-Adrim, 6th ed. (Bairut: Darul Kutup, 1419), 277.
} 
Allah SWT memberi informasi kepada umat manusia melalui firman ini tentang bukti-bukti kuasa-Nya dalam menciptakan makhluk dengan tanpa perantara. Menurut ulama' tafsir, Ayat 20 QS. ArRuum memuat rancangan dan susunan bentuk makhluk ciptaanNya, dan kuasa Allah SWT untuk meng-adakan sekaligus kuasa meniadakan. Makhluk pertama berwujud manusia yang diciptakan adalah nabi Adam as. Selama disurga Nabi Adam as. dianugerahkan perempuan sebagai isteri bernama siti Hawa. Dari pasangan nabi Adam as. dan siti Hawa berkembang menjadi keluarga baru hingga sampai saat ini dan bahkan sampai hari akhir.

Setelah ayat 20 yaitu ayat 21 tentang pasangan. Laki-laki dan perempuan sama-sama makhluk ciptaan Allah SWT. Kedunya saling berpasangan, laki-laki berpasangan dengan perempuan, begitu pula sebaliknya. Apabila dipertanyakan, siapakah yang lahir terlebih dulu antara laki-laki atau perempuan? jawabannya jelas, laki-laki lahir lebih dulu sebagaimana nabi Adam as. Dari sini dapat disimpulkan bahwa perempuan sejatinya bagian dari laki-laki, dan apabila kedua nya dipertemukan dalam bingkai pernikahan maka berarti laki-laki dipertemukan kembali dengan bagiannya sendiri, yaitu perempuan yang menjadi istrinya. Keterangan ini sesuai dengan ayat 21 QS. ArRuum tentang penciptaan pasangan laki-laki.

Kemudian pada ayat sebelumnya, yaitu ayat 22 sampai 24 QS ar-Ruum, Allah SWT juga berfirman tentang ciptaan. Ayat 22;

\section{Dan di antara tanda-tanda kekuasaan-Nya ialah menciptakan langit dan bumi dan berlain-lainan bahasamu dan warna kulitmu. Sesunggubnya pada yang demikan itu benar-benar terdapat tanda- tanda bagi orang-orang yang mengetahui.}

Firman Allah SWT pada ayat 22 QS. Ar-Ruum juga berbicara tentang penciptaan. Tema pada ayat ini berbeda dari sesudahnya, yaitu tentang penciptaan alam semesta, seperti beberapa langit, bumi, bentuk bahasa dan warna kulit.

Menurut ahli tafsir maksud ayat 22 adalah tidak ada satupun dimuka bumi yang mampu melemahkan Allah SWT. Makhluk yang hidup akan mati jika Allah SWT berkehendak demikian, dan sebaliknya bagi yang telah mati akan hidup kembali. ${ }^{19}$ Allah SWT maha kuasa menciptakan langit dan bumi seperti yang kita lihat

${ }^{19}$ Muhamad Bin Jarir, Jami'u Al-Bayan Fii Ta'wili Al-Qur'an, 20th ed. (t.t: t.p., n.d.), 87. 
menggunakan mata kepala dan mata hati (perenungan), tidak ada yang dapat menghalangi kehendak-Nya.

Selanjutnya ayat 23 dan 24 QS. Ar-Ruum berbunyi:

Dan di antara tanda-tanda kekuasaan-Nya ialah tidurmu di waktu malam dan siang hari dan usahamu mencari sebagian dari karuniaNya. Sesunggubnya pada yang demikian itu benar-benar terdapat tanda-tanda bagi kaum yang mendengarkan.

Dan di antara tanda-tanda kekuasaan-Nya, Dia memperlibatkan kepadamu kilat untuk (menimbulkan) ketakutan dan harapan, dan Dia menurunkan bujan dari langit, lalu mengbidupkan bumi dengan air itu sesudah matinya. Sesunggubnya pada yang demikian itu benarbenar terdapat tanda-tanda bagi kaum yang mempergunakan akalnya.

Ayat 23 dan 24 QS ar-Ruum berbeda dengan ayat sesudahnya. Dua ayat ini tidak menyinggung masalah penciptaan seperti ayat yang lain, namun secara substansi kedua ayat 23 dan 24 sama-sama menjelaskan tentang tanda-tanda keesaan Allah SWT. Ahli tafsir berpendapat tentang ayat 23, bahwa Allah SWT menetapkan jam dan waktu, kemudian jam dan waktu tersebut dibagi dua, pertama waktu malam dan kedua waktu siang, waktu malam untuk beristirahat, sedangkan waktu siang untuk bekerja. ${ }^{20}$ Penciptakan seluruh makhluk di muka bumi pasti ada fungsi dan manfaatnya, tidak ada satupun yang tidak bernilai. Tugas menusia berfikir dan berproses untuk menemukan fungsi dan manfaat tersebut, agar ekosistem kehidupan terus berjalan.

Dari keterangan di atas bisa diambil kesimpulan, bahwa ayat 20 sampai 24 QS. Ar-Ruum menjelaskan tentang keesaan dan kekuasaan Allah SWT. Perincian penafsiran keesaan dan kekuasaan Allah SWT pada masing-masing ayat berbeda-beda, susunan ayat 20, 21 dan ayat 22 menggunakan kalimat penciptaan berupa (khalaqab), sedangkan ayat 23 dan 24 tidak menggunakan susunan kalimat penciptaan.

B. Konsep Jodoh, Sakinah, Mawadah, dan Rahmat dalam Teks alQur'an

Pada pembahasan sebelumnya dikaji hubungan masing-masing ayat QS. Ar-Ruum, dari ayat 20 sampai 24. Selanjutnya pada pembahasan ini kajian lebih spesifik pada konsep jodoh, Sakinah, Mawadah, dan Rahmah.

${ }^{20}$ Ibid, 87

208 Fawait Syaiful Rahman - Kontekstualisasi Konsep Jodoh, Sakinah 
Konsep jodoh dan konsep Sakinah, Mawadah, Warahmah disebutkan dalam ayat 21 QS ar-Ruum. Konsep jodoh dan konsep sakinah, mawadah, warahmah di dalam ayat 21 disebutkan dengan kalimat berbeda. Penyebutan jodoh menggunakan kalimat khalaqah, sedangkan penyebutan konsep sakinah, mawadah, warahmah menggunakan kalimat ja'ala. Perbedaan kalimat dalam pengungkapan sesuatu dalam bahasa arab memiliki konsekuensi hukum sendiri, seperti pada konsep jodoh disebutkan dengan kalimat khalawah, dan konsep sakinah, mawadah, warahmah disebutkan dengan kalimat ja'ala.

Di dalam kamus al-Munawwir pengertian kalimat khalaqah adalah penciptaan. ${ }^{21}$ Sedangkan di dalam kamus Arab Indonesia pengertian khalaqah berarti menciptakan, membuat, memulai, mengahasilkan, melahirkan, membangkitkan, menimbulkan, menyebabkan, dan menerbitkan. ${ }^{22}$ Sedangkan di dalam kamus mu'jamu al-mu'asyaroh pengertian khalaqah adalah memulai atau menciptakan sesuatu tanpa ada kembarannya, tidak ada perkara lain yang sama dengannya, atau menjadikan sesuatu dari tidak ada menjadi ada. Dari beberapa pengertian tentang kalimat khalaqah dapat disimpulkan bahwa sesuatu yang diungkapkan menggunakan kalimat khalaqah menunjukkan bahwa sesuatu tersebut hanya dilakukan oleh Allah SWT. Seperti penciptaan bumi dan langit, penciptaan manusia dari debu, dan bentuk bahasa sekaligus warna kulit, semuanya tidak ada intervensi manusia.

Salah satu perkara yang diungkapkan menggunakan kalimat khalaqah adalah penciptaan perempuan yang menjadi jodoh bagi laki-laki. Di dalam ayat 21 QS. Ar-Ruum disebutkan tentang penciptaan perempuan;

Dia menciptakan untukmu isteri-isteri dari jenismu sendiri

Menurut Ibrahim Bin Siri Bin Sahl di dalam kitab tafsir Ma'ani alQur'an Wa I'rabubu Li Zujaji yang dimaksud dengan kalimat min anfusikum adalah dari tulang rusuk kalian semua. ${ }^{23}$ Siti Hawa diciptakan oleh Allah SWT ke muka bumi dari tulang rusuk Nabi Ada as. Apabila penciptaan siti Hawa dikontektualisasikan dalam kehidupan sekarang kurang relevan, karena laki-laki dan perempuan dilahirkan dari rahim ibu dari hubungan suami istri. Perantara

${ }^{21}$ W.A Munawwir, "Kamus Al-Munawwir," in Kamus Al-Munawwir, 1984, 363.

22 Aplikasi Kamus Arab Indonesia Lite, Versi 6.0.1

${ }^{23}$ Ibrahim Bin Siri Bin Sahl, Ma'ani Al-Qur'an Wa I'rabubu Li Zujaji, 4th ed. (t.t.: Bairut, 1988), 182. 
penciptaan laki-laki dan perempuan diawali dari hubungan suami istri melalui pertemuan sperma laki-laki dan sel telur perempuan, keduanya bertemu dan menempel pada rahim perempuan sampai terjadi pembuahan. Proses penciptaan manusia saat ini berbeda dengan penciptaan siti Hawa, namun substansi dari ayat 21 QS arRuum berbicara sama, pertama ayat 21 QS ar-Ruum menjalaskan tentang penciptaan siti Hawa dari tulang rusuk nabi Adam as. dan kedua siti Hawa menjadi jodoh dari nabi Adam as.

Kalimat khalaqah di dalam ayat 21 QS ar-Ruum secara tidak langsung berbicara tentang jodoh antara laki-laki dan perempuan, melalui penjelasan proses penciptaan siti Hawa. Berbagai referensi menyatakan bahwa siti Hawa diciptakan oleh Allah SWT dengan tanpa ada campur tangan dari nabi Adam as atau makhluk ciptaan lainnya. Tujuan Allah SWT menciptakan siti Hawa sebagai istri atau pasangan nabi Adam as. dari uraian ini menjadi jelas bahwa permasalahan jodoh manusia menjadi hak priogratif Allah SWT sebagaimana proses penciptaan siti Hawa, dan manusia tidak memiliki daya upaya untuk menentukan jodohnya sendiri. Secara aksiomatis, panciptaan manusia dan bumi sekaligus isinya menjadi urusan Allah SWT tidak terbantahkan, seperti keterangan di dalam ayat 20 dan ayat 22 QS. Ar-Ruum.

Selanjutnya konsep sakinah, mawadah, warahmah disebutkan pada potongan ayat 21 QS ar-Ruum sebagai berikut;

"Supaya kamu cenderung dan merasa tenteram kepadanya, dan dijadikan-Nya diantaramu rasa kasib dan sayang.

Alasan penciptaan perempuan telah disebutkan menggunakan kalimat Yaskunu dari asal kata sakana. Di dalam kamus bahasa arab arti dari sakana bervariatif, sakana bermakna tinggal di, berada, menempati, mendiami. ${ }^{24}$ Menurut tafsir Samarqandi yang dimaksud dengan yaskunu adalah wafaqa-yuwafiqu, artinya mencocokkan atau menyesuaikan, dan yaskunu juga dimaknai dengan istaqarra-yastaqirru bermakna stabilitas. Apabila Yaskunu diartikan dengan Yuwafiqu maka bermakna laki-laki harus menyesuaikan diri pada karakter seorang istri yang berbeda-beda., Dan apabila Yaskunu diartikan dengan Yastaqirru bermakna stabilitas berarti istri dapat menstabilkan hati suami, sehingga tidak gonjang-ganjing. ${ }^{25}$ Pengertian Yaskunu di

\footnotetext{
${ }^{24}$ Aplikasi Kamus Arab Indonesia Lite, Versi 6.0.1

25 Secara umum apabila laki-laki bepergian berkeliling daerah, perpindah-pindah pekerjaan, hatinya seringkali tidak fokus atau tidak terarah, dan ketika kembali pada keluarga dirumah membuat suasana hatinya kembali tenang dan fokus.
} 
dalam kitab Tafsir al-Qur'an al-Aziz bermakna ista'nasa, yaitu bersenang-senang, ${ }^{26}$ perempuan memiliki sesuatu yang membuat laki-laki senang, dan sebaliknya perempuan juga memerlukan lakilaki untuk membuat dirinya sendiri senang.

Berikutnya konsep mawadah wa rahmah. Pada ayat 21 arRuum konsep mawadah dan rahmah diungkapkan menggunakan kalimat ja'ala bermakna membuat atau menjadikan, berbeda dengan penyebutan konsep jodoh menggunakan kalimat khalaqah. Kalimat ja'ala memiliki kemiripan arti dengan khalaqah, yaitu sama-sama menjadikan sesuatu. Namun ada juga perbedaan diantara keduanya, kalimat khalaqah dipakai untuk sesuatu yang hanya dilakukan oleh dzat tunggal yaitu Allah SWT, seperti penciptaan bumi dan langit, penciptaan warna kulit, bentuk bahasa dan perkara lainnya. Sedangkan kalimat ja'ala dipakai untuk sesuatu yang dilakukan dengan campur tangan manusia.

Mawadah secara bahasa bermakna cinta kasih dan rahmah bermakna kasih sayang, berempati, ramah dan toleransi. Pengertian mawadah di dalam kitab-kitab tafsir dimaknai dengan senggama atau persetubuhan, sedangkan rahmah dimaknai dengan anak. ${ }^{27}$ Menurut Hasan, mawadah adalah kecintaan suami kepada istri, sedangkan rahmah bermakna rasa empati suami apabila istri mendapat musibah. ${ }^{28}$ Pengertian mawadah juga disebutkan dalam kitab Siraju al-Munir Fii al-I'ana bermakna "perasaan tidak suka bagi masingmasing suami istri apabila diantara mereka mendapat musibah atau sesuatu yang menyakiti, dan pengertian rahmah adalah upaya dari masing-masing pasangan untuk membahagiakan satu sama lain dengan menghilangkan sesuatu yang dapat menyakiti. ${ }^{29}$

Pengungkapan dua konsep jodoh dan sakinah, mawadah, warahmah berbeda di dalam al-Qur'an. Konsep jodoh diungkapkan dengan kalimat khalaqah, sedangkan konsep sakinah, mawadah, warahmah disebutkan menggunakan kalimat ja'ala. Perbedaan dalam pengungkapan antara khalaqah dan ja'ala memiliki konsekuensi terhadap status dan ikatan pernikahan. Konsep jodoh yang diungkapkan dengan kalimat khalaqah bermakna jodoh manusia hanya ditentukan oleh Allah SWT, dan konsep sakinah, mawadah, warahmah diungkapkan dengan kalimat ja'ala bermakna kerukunan

\footnotetext{
26 Abu Abdillai, Tafsir Al-Qur'an Al-Ariz (Mesir, 2002), 359.

${ }^{27}$ Muhammad Bin Ali Bin Muhammad Bin Abdillah As-Syaukani, Fath Al-Qadir asSyaukani (Bairut, 1414), 253.

${ }^{28} \mathrm{Ibid}, 253$

${ }^{29}$ Syamsu Ad-Din, Siraju Al-Munir Fii Al-I'ana (t.t.: t.p, 1285), 162.
} 
hubungan suami istri harus dibangun bersama, menciptakan nuansa rukun perlu adanya usaha maksimal dari masing-masing pasangan agar hubungan keduanya tenteram, dan damai.

\section{Kesimpulan}

Dari hasil kajian dan analisis teks, disimpulkan bahwa penyebutan konsep jodoh dan konsep sakinah, mawadah, warahmah di dalam alQur'an berbeda. Konsep jodoh difirmankan menggunakan bahasa arab khalaqah dengan makna menciptakan dari tidak ada menjadi ada. Sedangkan konsep sakinah, mawadah, warahmah difirmankan menggunakan bahasa arab ja'ala dengan arti menjadikan sesuatu dari sudah ada menjadi perkara lain. Jodoh menjadi hak priogratif Allah SWT, sedangkan membangun keluarga sakinah, mawadah, warahmah harus dibangun oleh suami istri. Konsep jodoh dan konsep sakinah, mawadah, warahmah di dalam pernikahan bukan satu kesatuan. Jodoh merupakan perkara lain dan sakinah, mawadah, warahmah juga perkara lain, kedua konsep tersebut di dalam pernikahan bisa bertemu dan bisa juga tidak. Pasangan suami istri yang berjodoh dapat bertahan hingga akhir hayat meskipun hubungannya tidak rukun., dan sebaliknya apabila suami istri dapat membangun sakinah, mawadah, warahmah di dalam pernikahannya maka hubungan keduanya dapat berakhir ditengah jalan meski sudah rukun.

\section{Daftar Pustaka}

Abdillai, Abu. Tafsir Al-Qur'an Al-Aziz: Mesir, 2002.

Abdillau, Muhallab Bin Ahmad Bin Abi Sufrah Asid Bin. Mubktasor AlNasib Fii Tabdribi Al-Kitab Al-Jami' Al-Shabih. 2nd ed. Riyadl: Daru al-Ttauhid, 1430.

Ad-Din, Syamsu. Siraju Al-Munir Fii Al-I'ana. t.t.p.,: t.t., 1285.

Al-Aziz, Umar Bin Abdu. An-Naqsu Mina an-Nassi Hakiqatu Wa Hikmatubu Wa Astaru Dralika Bi Al-Ibtijaji Bi as-Sunati AlHadiyati. 1st ed. Madinah: t.p., 1988.

As-Syaukani, Muhammad Bin Ali Bin Muhammad Bin Abdillah. Fath AlQadir as-Syankani. Bairut, 1414.

Ibrahim, Abu Ya'kub Ishaq Bin. Musnad Ishaq Bin Ruhawiyah. 2nd ed. Madinah: Maktabatu al-Iman, 1412.

Ismail, Abu al-Fada'. Tasfir Al-Qur'an Al-Adrim. 6th ed. Bairut: Darul Kutup, 1419.

Jarir, Muhamad Bin. Jami'u Al-Bayan Fii Ta'wili Al-Qur'an. 20th ed. t.t: 


$$
\text { t.p., n.d. }
$$

Munawwir, W.A. “Kamus Al-Munawwir.” In Kamus Al-Munawwir, 1123, 1984.

Rahman, Fawait Syaiful. "Analisis Maqashid Syari'ah Jasser Auda Terhadap Izin Perkawinan Dan Perceraian Bagi Pegawai Negeri Sipil." Momentum : Jurnal Sosial Dan Keagamaan 7, no. 1 (2019): 3558. https://doi.org/10.29062/mmt.v7i1.15.

Sahl, Ibrahim Bin Siri Bin. Ma'ani Al-Qur'an Wa I'rabubu Li Zujaji. 4th ed. t.t.: Bairut, 1988. 
